\title{
A Characterization Method for Al Recovery from Dross Based on Compression at Elevated Temperatures
}

\author{
S. Maropoulos, D. Kountouras, X. Voulgaraki, S. Papanikolaou, and I. Sanaidis \\ Mechanical Engineering Department, Technical University of Western Macedonia, Koila, 50100 Kozani, Greece \\ Correspondence should be addressed to S. Maropoulos, maropou@teikoz.gr
}

Received 15 June 2011; Revised 20 September 2011; Accepted 26 September 2011

Academic Editor: Alexander Tsouknidas

Copyright () 2011 S. Maropoulos et al. This is an open access article distributed under the Creative Commons Attribution License, which permits unrestricted use, distribution, and reproduction in any medium, provided the original work is properly cited.

When aluminum or its alloys are melted, considerable amounts of dross are produced. The alloy type and the method used in the production of aluminum products play an important role in the amount of dross that will result as a byproduct. The current needs of the $\mathrm{Al}$ industry as well as economic and environmental factors demand the recovery of the pure material that is lost during dross removal by simple and efficient methods that can be applied within the foundry. Most cases of Al recovery employ methods of dross compression at high temperatures. This investigation attempts to develop a mathematical model to characterize the efficiency of the recovery process that can be implemented for any dross collection method or even compression device, facilitating the direct comparison of recovery methods.

\section{Introduction}

The continuous film formed on the surface of liquid Al, commonly referred to as dross, is a mixture of gasses, nitrides, carbides, and other substances, thus, partially partitioning to oxides $[1,2]$. Due to the high temperatures that are present, the development of the above compounds is favored. As a result, a percentage of approximately $1.5-2.5 \%$ [3] of the total amount of molten material is characterized as dross and removed from the liquid prior to casting. However, during the removal of dross, a certain amount of pure metal is trapped within its mass and is consequently wasted. Depending on the way dross is collected and removed from the foundry, it may contain up to $30-90 \%$ fully recyclable or recoverable aluminum $[4,5]$ while remaining $\mathrm{Al}$ oxides can be utilized in a series of other applications $[6,7]$.

The methods of dross removal in foundries are mainly empirical, hardly reproducible, and are carried out either manually or by automated mechanical methods. The criteria for implementing a dross collection method vary depending on economic and technical factors and the means available. Bearing in mind that the collected material is further processed in a number of ways, it is not an easy task to compare methods adapted by different foundries.
Recently there has been a continuously growing demand to recycle novel materials such as $\mathrm{Al}$, not only because of the depleting $\mathrm{Al}$-ore reserves but also due to the increasing effort to minimize the environmental footprint of industrial byproducts and waste.

The present investigation seeks to introduce a simple systematic way to compare $\mathrm{Al}$ recovery methods from dross based on compression at elevated temperatures regardless to the retrieval method or the employed device parameters. A mathematical model is developed, facilitating the characterization of the recovery process in terms of productivity.

\section{Experimental Procedure}

During dross collection, each lot of material taken may differ depending on a number of parameters such as removal speed, collection depth, and so forth. Most foundries employ automated [8] or manual collection by means of a mechanical ladle mounted on a clark or direct handling of the collection device by personnel [9]. In these cases the material removal process is not reproducible with regard to its composition since the aforementioned parameters cannot be kept constant as the surface shear of this procedure is described by rather complex phenomena [10]. 


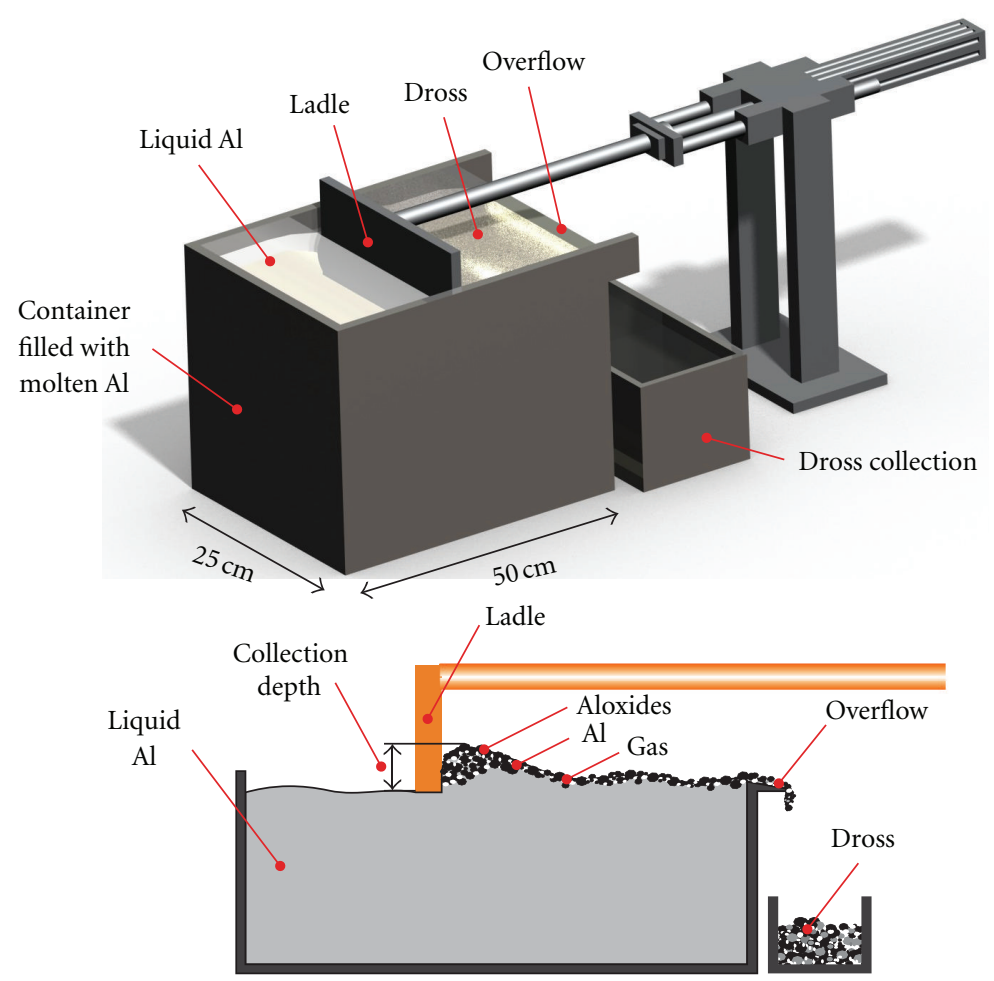

Figure 1: Automated dross collection.

Although the model which will be presented further on can characterize fluctuation processes, a laboratory scale setup, schematically presented in Figure 1, was developed to evaluate the effect of both collection depth and speed on the recovered material.

Two types of dross collection were considered in the present investigation, manual and automated (by means of the device shown in Figure 1). The collection speed of the automated procedure was kept constant, throughout each process, while two different ladle velocities were considered, 0.1 and $0.15 \mathrm{~m} / \mathrm{s}$. During the manual operation of the ladle, attention was given to maintain the collection speed within this range. This velocity range was selected to maintain the integrity of the oxide film, as higher collection speeds lead to tearing of this membrane. The dross was collected in a container receiving $180 \mathrm{gr}$ of material, and each experiment was terminated upon collecting this amount. This facilitated the direct comparison between all scenarios, varying in removal speed and ladle depth.

In order to ensure the proper formation of the oxide film on top of the molten aluminium after each removal process, consecutive experiments were conducted at 20-minute time intervals.

Every batch of dross taken was crashed and sieved prior to processing. Grains less than $1 \mathrm{~mm}$ in diameter were removed, while grains from $1 \mathrm{~mm}$ to $2 \mathrm{~cm}$ were used resulting in the final ground dross.

The ground dross was then placed in the heated cylindrical container, illustrated in Figure 2. The container design introduced represents an optimized geometry deriving from

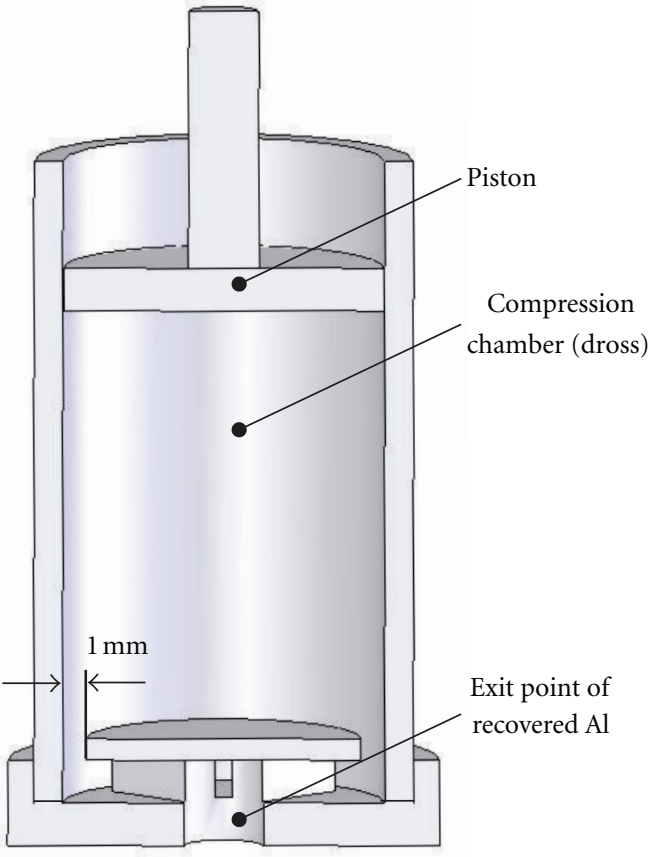

Figure 2: Cylinder used during $\mathrm{Al}$ recovery.

consecutive experiments with various piston bottoms (conical, multiple perforations and differing hole geometries, etc.). 
The final geometry consists of a $380 \mathrm{~mm}$ high cylinder with a $55 \mathrm{~mm}$ diameter and a $1 \mathrm{~mm}$ peripheral exit gap elevated by $3 \mathrm{~mm}$ from the cylinder bottom. The extrusion hole was $43 \mathrm{~mm}$ in diameter and $5 \mathrm{~mm}$ high.

The aforementioned cylinder was heated to $800^{\circ} \mathrm{C}$, prior to the experimental procedure, and the containing aluminium was compressed by a piston while the temperature was kept constant. The aluminum released from the dross flows through the small $1 \mathrm{~mm}$ peripheral gap in the bottom part of the device and is collected in a container placed below the apparatus. This recovery procedure was chosen since compression of dross is a common practice during $\mathrm{Al}$ retrieval [11-13].

During the experiments, the maximum pressure was predefined based on calculations considering the friction of a semisolid material within an extrusion container [14]. The pressure was applied by the hydraulic parts of the experimental setup, thus forcing the piston to move. The experiment was stopped when there was no change in the piston movement for the maximum applied pressure. During the whole process, the control unit of the device registered the piston displacement versus the resulting forces.

\section{Mathematical Model of the Recovery Process}

There are a number of methods for the processing of dross which have been developed since 1980 [15]. Nevertheless the collection of dross is based on the same principle, either through levity overflow or by skimming. Dross is composed of oxides, salts, pores and pure metal, thus, its volume $V_{\text {total }}$ can be described by

$$
V_{\text {total }}=V_{\text {oxide }}+V_{\text {salt }}+V_{\text {pore }}+V_{\text {metal }}
$$

where $V_{\text {oxide }}$ is the volume of the oxides contained, $V_{\text {salt }}$ the volume taken up by salt, $V_{\text {pore }}$ the volume of the pores contained in the material which is usually air or foundry gases and finally, and $V_{\text {metal }}$ the volume of trapped metal.

The mechanical characteristic presenting the highest impact on the recovery process is the pressure at which the metal will drain from the oxides-salts. The morphology of the dross containing pores, ceramics (oxides), and $\mathrm{Al}$ resembles that of metal matrix composite materials.

As this is compressed, $\mathrm{Al}$ is removed and its measure of elasticity is constantly altered. The pores within the dross decrease, finally resulting in a mixture of oxides and salt which constitute the final measure of elasticity. It is worth mentioning that the relationship of the elasticity modulus of the composite material depends on the composition in metal pores and conglomerated oxides-salts.

Applying the rule of mixing (ROM) to (1) provides the elasticity modulus of this composite material $(E)$ given by

$$
E_{\text {total }}=a \times E_{\text {oxide }}+b \times E_{\text {salt }}+c \times E_{\text {metal }},
$$

where $a, b$, and $c$ are the volume percentage of oxides, salt and $\mathrm{Al}$, respectively, and $E_{\text {oxide, }}, E_{\text {salt }}$, and $E_{\text {metal }}$ the elasticity modulus of oxides, salt and Al. The volume percentage taken up by pores and gases is not taken into account in (2) since it does not modulate the materials elasticity modulus.

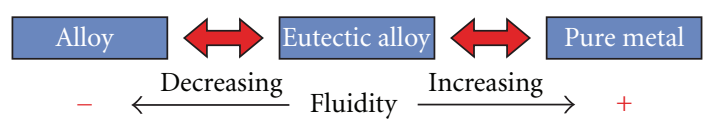

FIGURE 3: Fluidity dependency of metals based on composition.

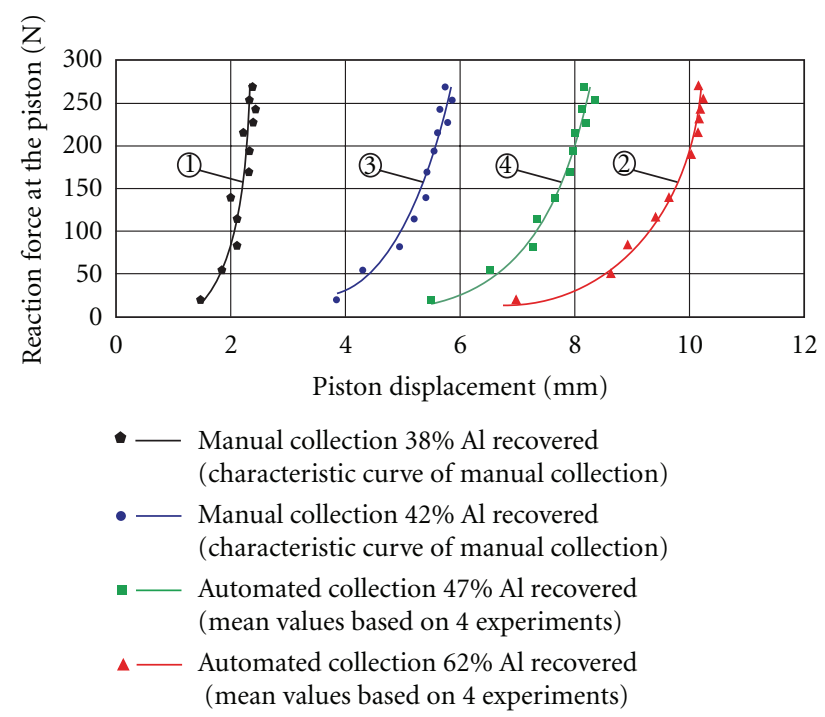

Figure 4: Experimentally determined values for 4 varying cases with the first method of a single collecting process per sample.

The fluidity of the collected material is a parameter strongly affecting the recovery process. Increased fluidity eases the procedure and improves the efficiency. The alloy components play a particular role in determining the fluidity, as does the temperature. The fluidity dependency of metals based on composition can be described by Figure 3 [16]. Based on this, the collected dross is additionally heated over the metal melting point during the recovery process to further increase the fluidity of the material.

During the compression of the recovered $\mathrm{Al}$, the reaction force of the piston versus its displacement can be graphically presented as shown in Figure 4. Curves 1 and 3 represent characteristic manual dross collections selected from 40 experiments in total. They show the typical behavior exhibited by the experimental procedure. On the other hand, curves 2 and 4 relate to the automated collection and are the mean values of 4 experiments for each of the selected process parameters (collection speed, depth, etc.).

The experiments were repeated as there was no reproducibility in either collection method, due to the hydrodynamic effect of the subsurface liquid interacting in various ways with the oxide film collected.

The curves presented in Figure 4 show the tendency of the elasticity modulus of composite materials $[17,18]$.

The depths of cleaning in each sample are shown in Table 1.

Figure 5 shows the relationship between the percentage of recovered material and the depth of collection. By considering point $\mathrm{A}$ as the ideal process and $\mathrm{B}$ as the sloppy cleaning process, then $\mathrm{AB}$ is considered as the distance 
TABLE 1: Cleaning depths of the experiments.

\begin{tabular}{llcll}
\hline Experiment & 1 & 2 & 3 & 4 \\
\hline Depth $(\mathrm{mm})$ & 4 & 12 & 6 & 8 \\
\hline
\end{tabular}

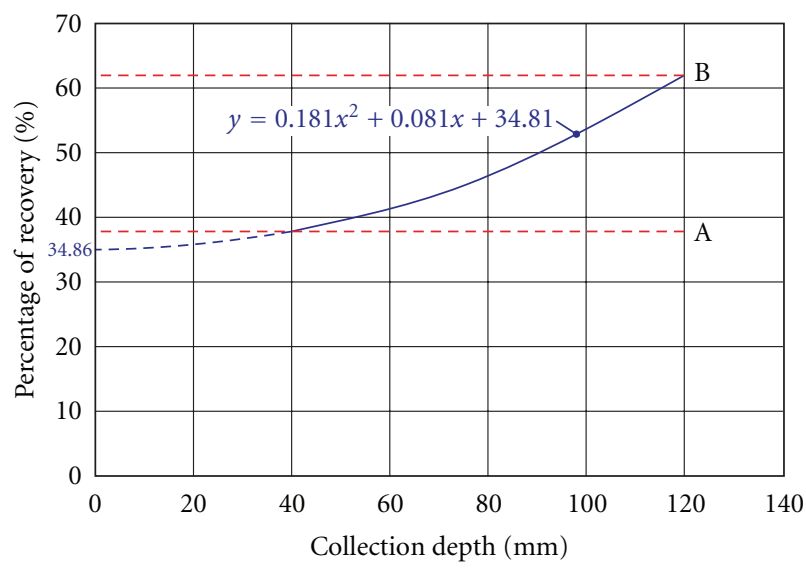

Figure 5: Percentage of recovery in relation to the depth of collection.

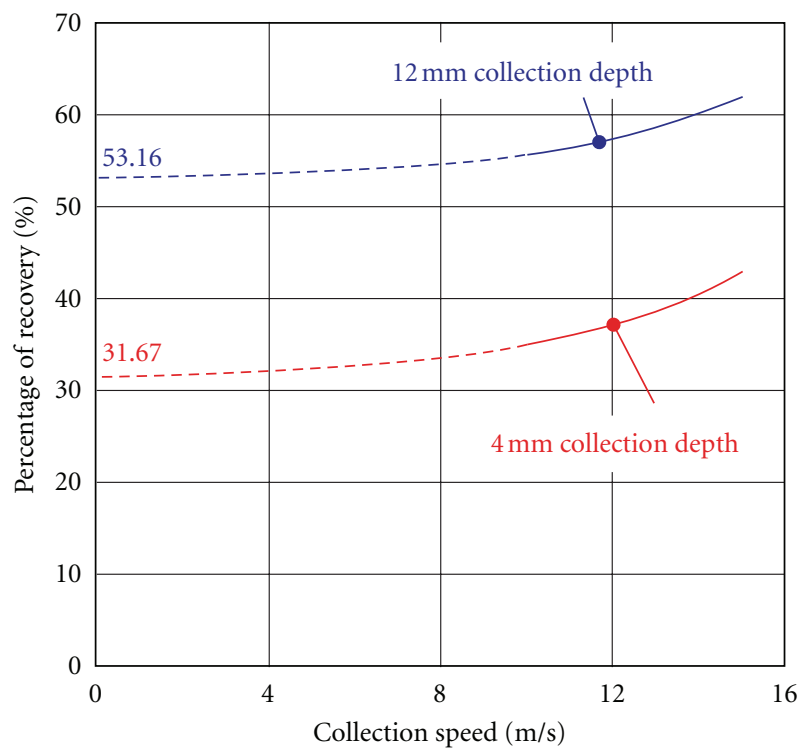

FIGURE 6: The dependence of percentage of recovery on collection speed.

between perfection and sloppiness of collection in the specific experiment.

A double derivative of the equation shown in Figure 5 gives the minimum value of the curve which defines the minimum thickness of oxides that could be collected with the above procedure at $0.36 \mathrm{~mm}$. Submerging the ladle at this depth during the automated processes results in a $32.1 \%$ percentage of $\mathrm{Al}$ recovery, which agrees well with the $34.86 \%$ corresponding to the theoretical optimum shown by the curve in Figure 5.

The dependence of percentage of recovery on collection speed is shown in Figure 6. As can be seen, the effect of the collection speed remains constant regardless of the collection depth selected.

\section{Results and Discussion}

A significant increase of collection speed would lead to tearing of the continuous film formed on the surface of liquid $\mathrm{Al}$ while forcing pure $\mathrm{Al}$ to drift along, thus, collecting more pure material rather than dross decreasing the efficiency and increasing the percentage of $\mathrm{Al}$ recovered. Increasing the collection depth follows the same principle; the deeper the ladle enters into the molten $\mathrm{Al}$, the more pure $\mathrm{Al}$ is collected thus rendering the process less productive.

\section{Conclusions}

The presented approach to $\mathrm{Al}$ recovery proves that the percentage of recovered material is not indicative of the process quality since it may be attributed to overcollecting of pure Al. In order to compare a variety of reclaiming processes, the productivity of the process has to be considered.

\section{References}

[1] Q. Han, W. Simpson, J. Zeh, E. Hatfield, and V. K. Sikka, "Dross formation during remelting of aluminum 5182 remelt secondary ingot (RSI)," Materials Science and Engineering A, vol. 363, no. 1-2, pp. 9-14, 2003.

[2] O. Manfredi, W. Wuth, and I. Bohlinger, "Characterizing the physical and chemical properties of aluminum dross," Journal of Material, vol. 49, no. 11, pp. 48-51, 1997.

[3] J. Mukhopadhyay, Y. V. Ramana, and U. Singh, "Extraction of value added products from Aluminium dross material to achieve zero waste," Light Metals, pp. 1209-1212, 2005.

[4] V. Kevorkijan, "Evaluating the aluminum content of pressed dross," Journal of Material, vol. 54, no. 2, pp. 34-36, 2002.

[5] S. Wang, H. Hu, Y. l. Chu, and P. Cheng, "Dross recovery of Aluminum alloy 380," in Proceedings of the CastExpo, Atlanta, Ga, USA, May 2008.

[6] K.-D. Bouzakis, E. Bouzakis, G. Skordaris et al., "Effect of PVD films wet micro-blasting by various $\mathrm{Al} 2 \mathrm{O} 3$ grain sizes on the wear behaviour of coated tools," Surface and Coatings Technology, vol. 205, supplement 2, pp. S128-S132, 2011.

[7] K. -D. Bouzakis, G. Skordaris, E. Bouzakis et al., "Optimization of wet micro-blasting on PVD films with various grain materials for improving the coated tools' cutting performance," CIRP Annals, vol. 60, no. 1, pp. 587-590, 2011.

[8] "Robotic dross removal melts away labor pain," Manufacturing Engineering, vol. 124, no. 6, 2000.

[9] M. Ueda, S. Tsukamoto, S. Konda, and T. Ohtsuka, "Recovery of aluminum from oxide particles in aluminum dross using $\mathrm{AlF}_{3}-\mathrm{NaF}-\mathrm{BaCl}_{2}$ molten salt," Journal of Applied Electrochemistry, vol. 35, no. 9, pp. 925-930, 2005.

[10] K. D. Bouzakis, A. Tsouknidas, and G. Maliaris, "A wire cutting test to check the temperature distribution in inductively heated cylindrical aluminium billets at semi-solid material state," Journal of Materials Processing Technology, vol. 210, no. 1, pp. 166-173, 2010.

[11] J. Julliard, L. Tirilly, and P. Vigier, "Apparatus for the recovery of liquid Aluminium by compression of hot dross," US Patent 4575056, 1986. 
[12] J. Shen, S. S. Xie, and J. H. Tang, "Dynamic recovery and dynamic recrystallization of 7005 aluminium alloy during hot compression," Acta Metallurgica Sinica, vol. 13, no. 1, pp. 379386, 2000.

[13] H. Yamagata, "Dynamic recrystallization and dynamic recovery in pure aluminum at 583K," Acta Metallurgica Et Materialia, vol. 43, no. 2, pp. 723-729, 1995.

[14] K. D. Bouzakis, K. Efstathiou, G. Paradisiadis, and A. Tsouknidas, "Experimental and FEM-supported investigation of wet ceramic clay extrusion for the determination of stress distributions on the applied tools' surfaces," Journal of the European Ceramic Society, vol. 28, no. 11, pp. 2117-2127, 2008.

[15] J. A. Taylor, J. F. Grandfield, and A. Prasad, "Dross processing technology," Materials Science Forum, vol. 630, pp. 53-60, 2009.

[16] K. R. Ravi, R. M. Pillai, K. R. Amaranathan, B. C. Pai, and M. Chakraborty, "Fluidity of aluminum alloys and composites: a review," Journal of Alloys and Compounds, vol. 456, no. 1-2, pp. 201-210, 2008.

[17] N. Michailidis, F. Stergioudi, A. Tsouknidas, and E. Pavlidou, "Compressive response of Al-foams produced via a powder sintering process based on a leachable space-holder material," Materials Science and Engineering A, vol. 528, no. 3, pp. 1662$1667,2011$.

[18] N. Michailidis, F. Stergioudi, and A. Tsouknidas, "Deformation and energy absorption properties of powder-metallurgy produced Al foams," Materials Science and Engineering A, vol. 528, no. 24, pp. 7222-7227, 2011. 

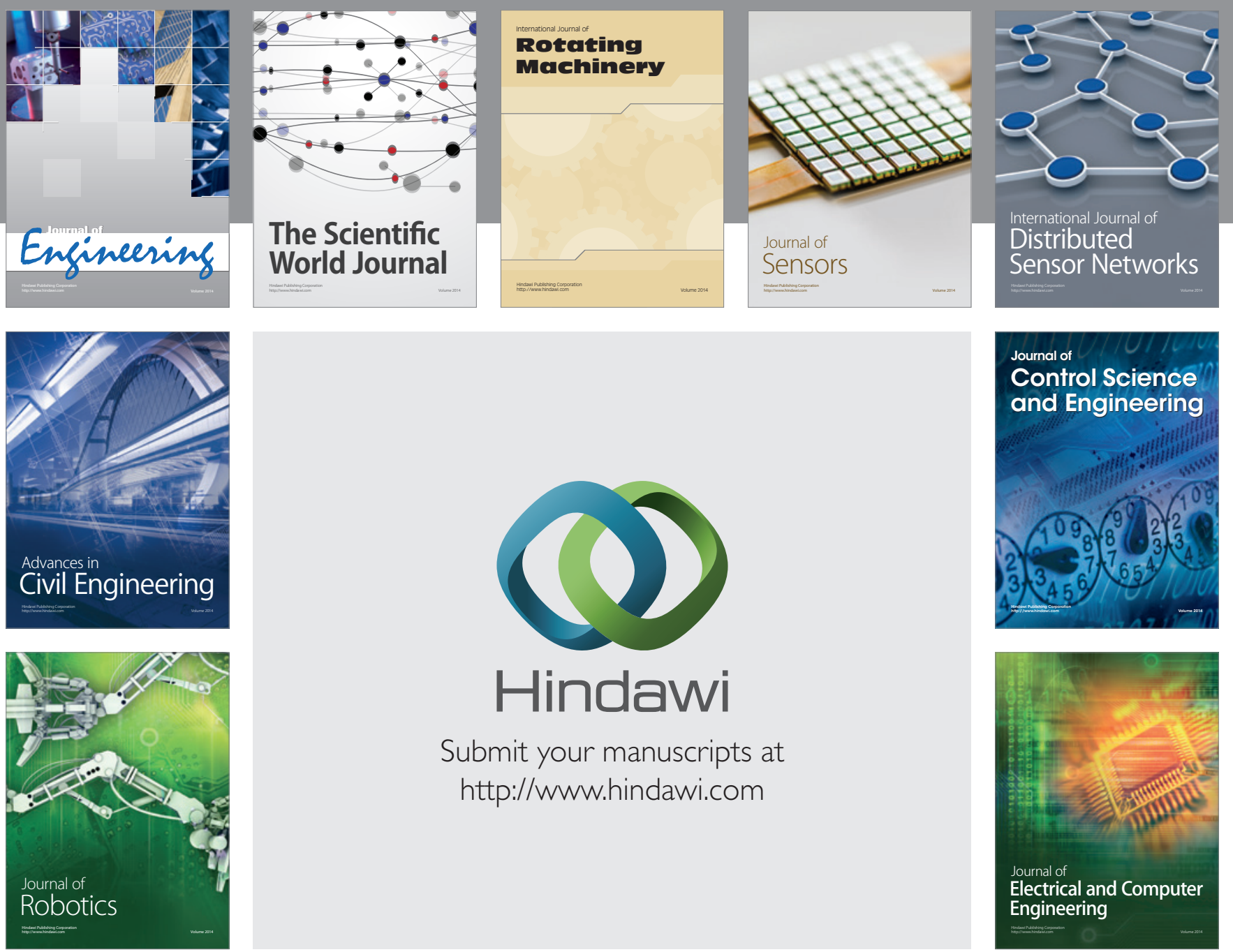

Submit your manuscripts at

http://www.hindawi.com
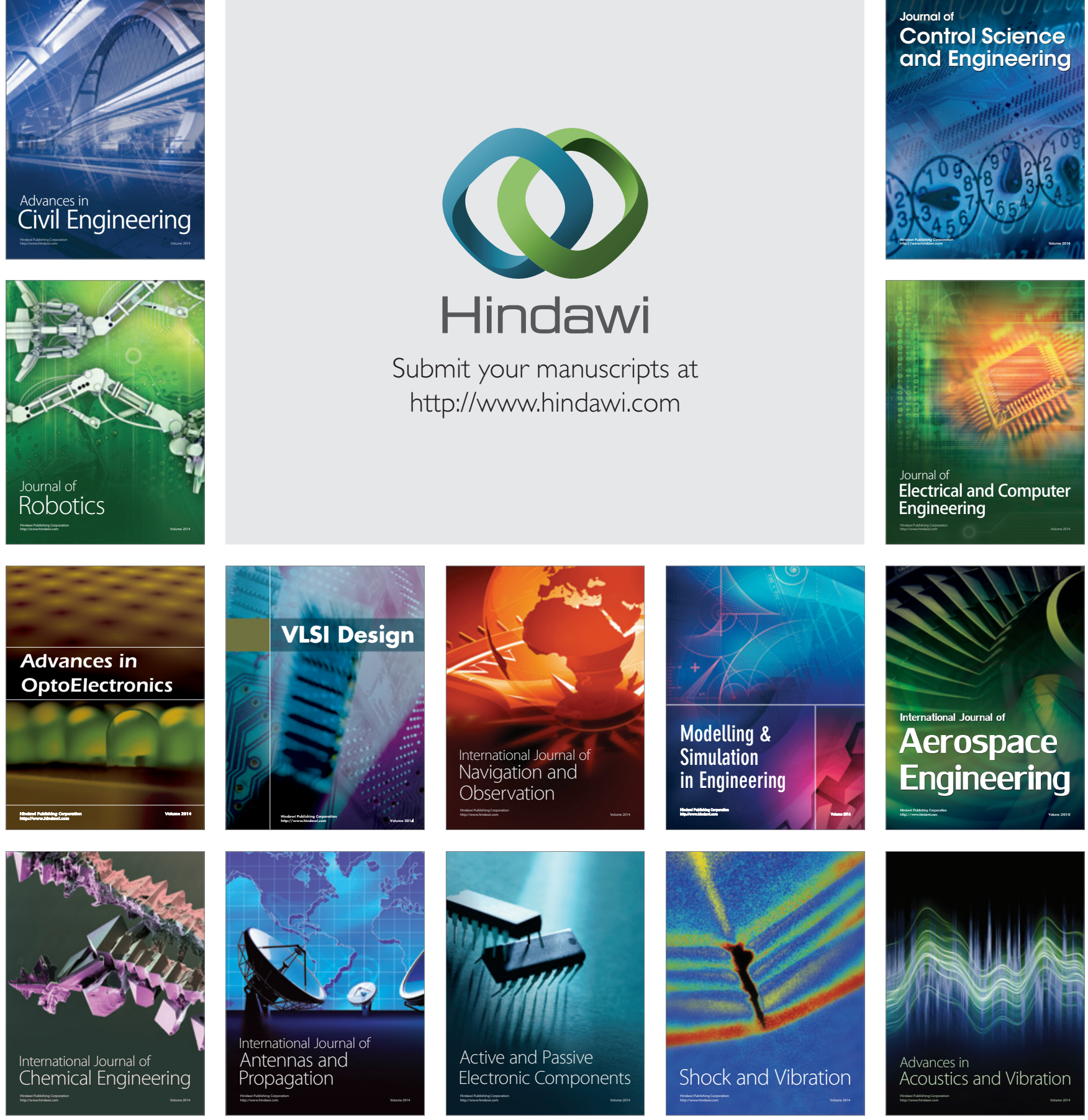